\title{
Performance Evaluation of Mixing Mechanism and its Effects on Thermal Behaviour of Plasticised PVC
}

\author{
Ali I. Al-Mosawi ${ }^{\# 1}$, Kálmán Marossy ${ }^{\# 2}$ \\ \# Polymers Department, Faculty of Materials Science and Engineering, \\ University of Miskolc, Miskolc, 3515 Egyetemváros, Hungary \\ 1. aliibrahim76@yahoo.com \\ 2 polka101@uni-miskolc.hu
}

\begin{abstract}
The effect of mixing by hand and mixing by mechanical mixer on limiting oxygen index, thermal stability and DSC of plasticised PVC has been studied in this article. LOI Stanton Redcroft FTA flammability unit, Stabilimetr PVC 03, and DSC823e were used for measuring limiting oxygen index and thermal stability of plasticised PVC. The experimental results showed that limiting oxygen index and thermal stability of plasticised PVC mixing by hand higher than mixing by mechanical mixer, because there is an irregular distribution of chlorine, carbon and oxygen elements inside the PVC structure, where there is a conglomeration of these elements at some points in case of mixing by hand and more homogeneous in case on mixing by mechanical mixer, as illustrated by scanning electron microscopy (SEM) images and the energy-dispersive $\mathrm{X}$-ray spectroscopic micro-analyzer (EDS). Therefore, this irregular distribution will give inaccurate results for limiting oxygen index of plasticised PVC.
\end{abstract}

Keywords - Plasticised PVC, Mixing type, LOI, Thermal stability, DSC, SEM, EDS

\section{INTRODUCTION}

The combustibility execution of PVC considered one of the important factors that the selection of this polymer in many applications depends on. It is possible to explain the reasons for the selection of PVC in applications that require high thermal resistance, by reference to its characteristic thermal properties, in addition to its generally have high chlorine content (56.7\%), also have a high affinity with a lot of flame retardants and smokesuppressant additives. There are different methods of additives action within PVC, where some act as catalysts with chlorine to generate non-flammable gases (free radicals), thus preventing oxygen from reaching the flame zone, or helps to form a char layer as in the case of smoke-suppressant additives.

These gases causes flame poison by free radicals and thereby limit its spread or even its eventual annihilation. The others needs heat energy to decomposition, which reduces the temperature of the surface of the material to a temperature below the degree of combustion, so the ignition will stop, and this called theory of thermal flammability [1-6]. PVC has low heat of combustion and it is an essential characteristic that gives it a preference over other plastics when flammability resistance is the basic choice for an appropriate application. The total heat emitted during combustion and the rate of this heat is one of the most important factors that control the actual spread of flame, which determines how can the materials fighting the fires [7-12].

\section{METHODOLOGY}

a. Materials: the main materials percentages were used in this article shown in Table.2. PVC S-5070 (Ongrovil@) supplied by BorsodChem Zrt., Hungary; Dioctyl Phthalate (DOP) as plasticizer supplied by DEZA, a. s. CO., Valašské Meziř́ičí, Czech Republic; Newstab-50 as calcium-zinc stabilizer which supplied by Betaquímica CO., Barcelona, Spain; and Wax-E (Licowax ${ }^{\circledR}$ E) as lubricant supplied by Clariant International Ltd, Muttenz Switzerland.

TABLE I. Composition of batches

\begin{tabular}{|c|c|c|c|c|}
\hline Material & PVC S-5070 & DOP & Newstab 50 & Wax-E \\
\hline Content, pphrr & 100 & 70 & 1.5 & 0.3 \\
\hline
\end{tabular}

b. Mixing process and preparation of samples: Two batches from PVC with some additives shown in Table.2, the samples materials in first batch were mixed by hand, and the samples materials in second batch mixing by mechanical mixer. The two batches were prepared by using the laboratory two roll mill (Schwabenthan) with forming conditions shown in Table.2 as sheets with $0.4-0.6 \mathrm{~mm}$ in thickness and then fabricated to the proper shapes by using hydraulic press at 300 and 20 bar pressure and temperature $175^{\circ} \mathrm{C}$ with $80 \mathrm{~mm}$ length, $10 \mathrm{~mm}$ width, and $4 \mathrm{~mm}$ thickness. 
TABLE II. Condition of rolling process

\begin{tabular}{|c|c|c|c|}
\hline Temperature & Time & \multicolumn{2}{|c|}{ Rolling speed } \\
\hline $170^{\circ} \mathrm{C}$ & $5 \mathrm{~min}$ & $21 \mathrm{rpm}$, Front roller & $24 \mathrm{pm}$, Back roller \\
\hline
\end{tabular}

c. Limiting oxygen index test: LOI was done by the instrument Stanton Redcroft FTA flammability unit with oxygen and nitrogen cylinders gas and accurate pressure control system found in BorsodChem company according to (ISO 4589-2) standard.

d. Thermal stability samples: (EN ISO 305) was used to fabricate thermal stability samples with $200 \mathrm{~mm}$ length, $15 \mathrm{~mm}$ width, and $0.4 \mathrm{~mm}$ thickness. This test is finishing within $2 \mathrm{hr}$ and temperature $190^{\circ} \mathrm{C}$, where the sample moves out of the Stabilemetr with velocity $2 \mathrm{~mm}$ per minute.

e. DSC test was performed with temperature range $30^{\circ} \mathrm{C}-240^{\circ} \mathrm{C}$, with $\mathrm{DSC} 823 \mathrm{e}$ instrument from Mettler Toledo found in BorsodChem. Samples weight was $10.5 \mathrm{~g}$.

f. Surface SEM-EDX analysis field emission scanning electron microscopy (FESEM) was used for the structural analysis of plasticised PVC. This test was done by using Carl Zeiss EVO MA10 SEM.

\section{RESULTS AND DISCUSSION}

Fig.1 represents the limiting oxygen index of plasticised PVC vs. mixing type. From the figure below we note that the value of the limiting oxygen index of the sample mixed by hand is higher than the value of the limiting oxygen index of the sample mixed by the mechanical mixer. Because the materials that are mixed by hand are conglomerated together inside the PVC structure and are difficult to see it, causing non homogeneous distribution of the elements so the results of the test is inaccurate and fluctuating, while for the mixing by the mechanical mixer, the distribution of the elements is fairly homogeneous.

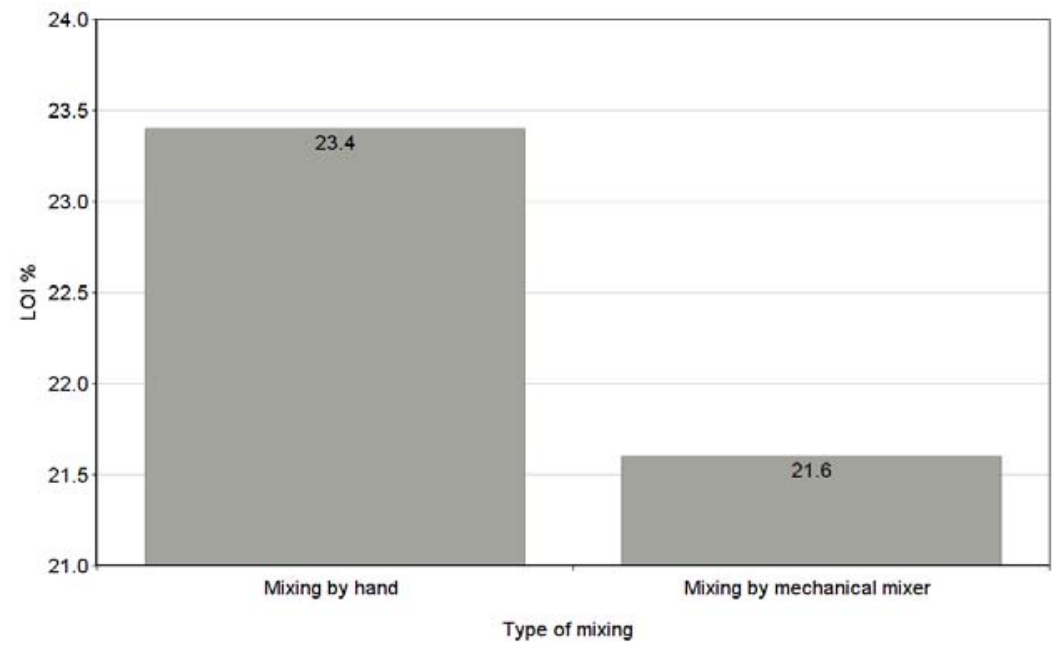

Fig.1 limiting oxygen index of plasticised PVC vs. mixing type

Thermal stability test of plasticised PVC at temperature $190^{\circ} \mathrm{C}$ vs. mixing type shown in Fig.2. The marks of this test will be a gradient colours series, where color of the sample is light and transparent when the test begins, because the beginning of the sample does not remain in the device for a long time therefore it is slightly affected by heat. And as we mentioned above, this test continue for two hours and the sample moves out of the device with velocity $2 \mathrm{~mm}$ per minute, so the color of the sample begins to change to dark color gradually. The color change depends on how long the sample remains inside the device, as it will change to pale yellow, then to yellowish orange, and by continuous testing the color changes to yellowish red, then changes to red color, then dark red, then brown, then the sample becomes dark. When comparing the color gradation between the two samples, we note that the thermal stability of the hand-mixed sample is better than the sample mixed by the mechanical mixer.

\begin{tabular}{|c|cccccccccc|}
\hline Sample minute & 10 & 20 & 30 & 40 & 50 & 60 & 70 & 80 & 90 & 100 \\
\hline $\begin{array}{c}\text { Mixing by mechanical } \\
\text { mixer }\end{array}$ & 11 & & & & & & & & & \\
\hline Mixing by hand
\end{tabular}

Fig.2 Thermal stability test of plasticised PVC at temperature $190^{\circ} \mathrm{C}$ vs. mixing type 
From the DSC measurement illustrated in Fig.3, we noted that the average value of the gelation grade of PVC mixing by mechanical mixer is higher than PVC mixing by hand, and this due to the plasticizer will penetrate within PVC particles with rotational movement of mixer and temperature causing swelling of these particles [13].

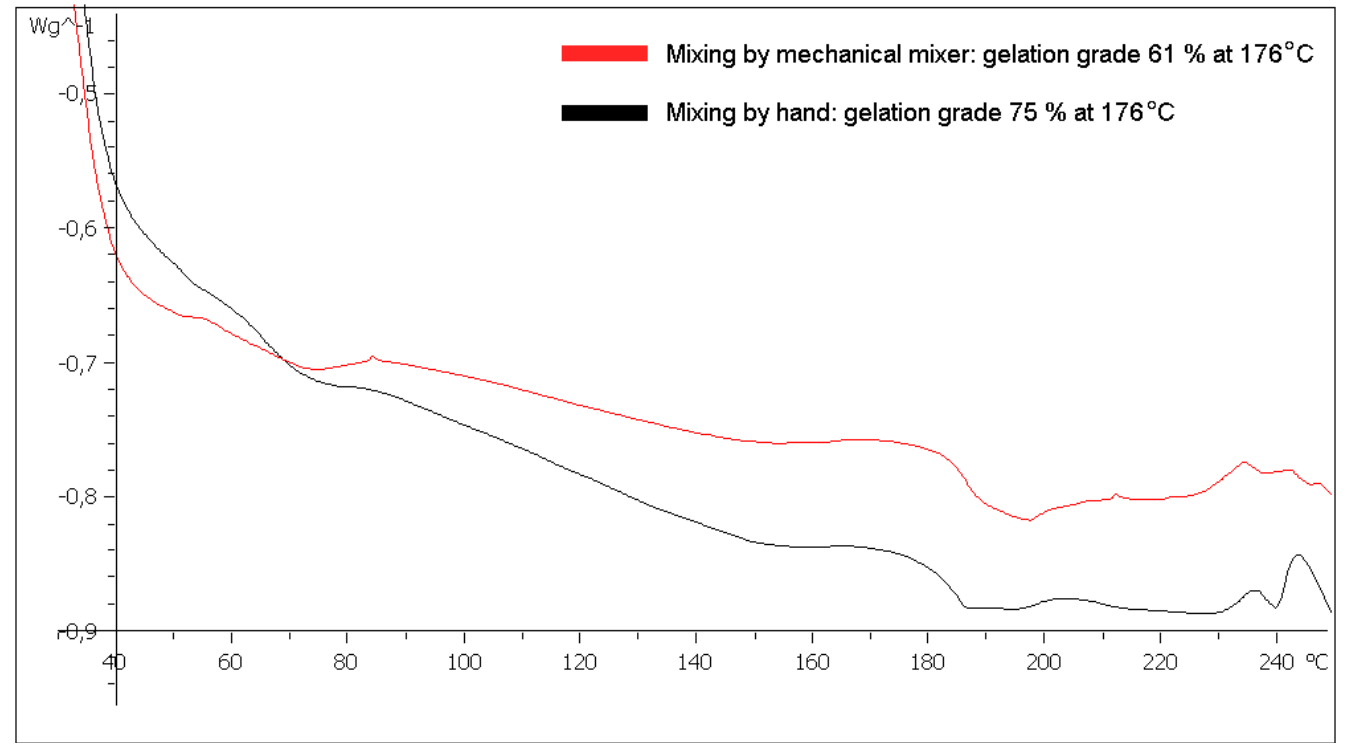

Fig.3 DSC measurement for hand and mechanical mixed plasticised PVC

This behavior was characterized by scanning electron microscopy (SEM) coupled with energy-dispersive Xray spectroscopic micro-analyser (EDS) as in Fig.4-13.

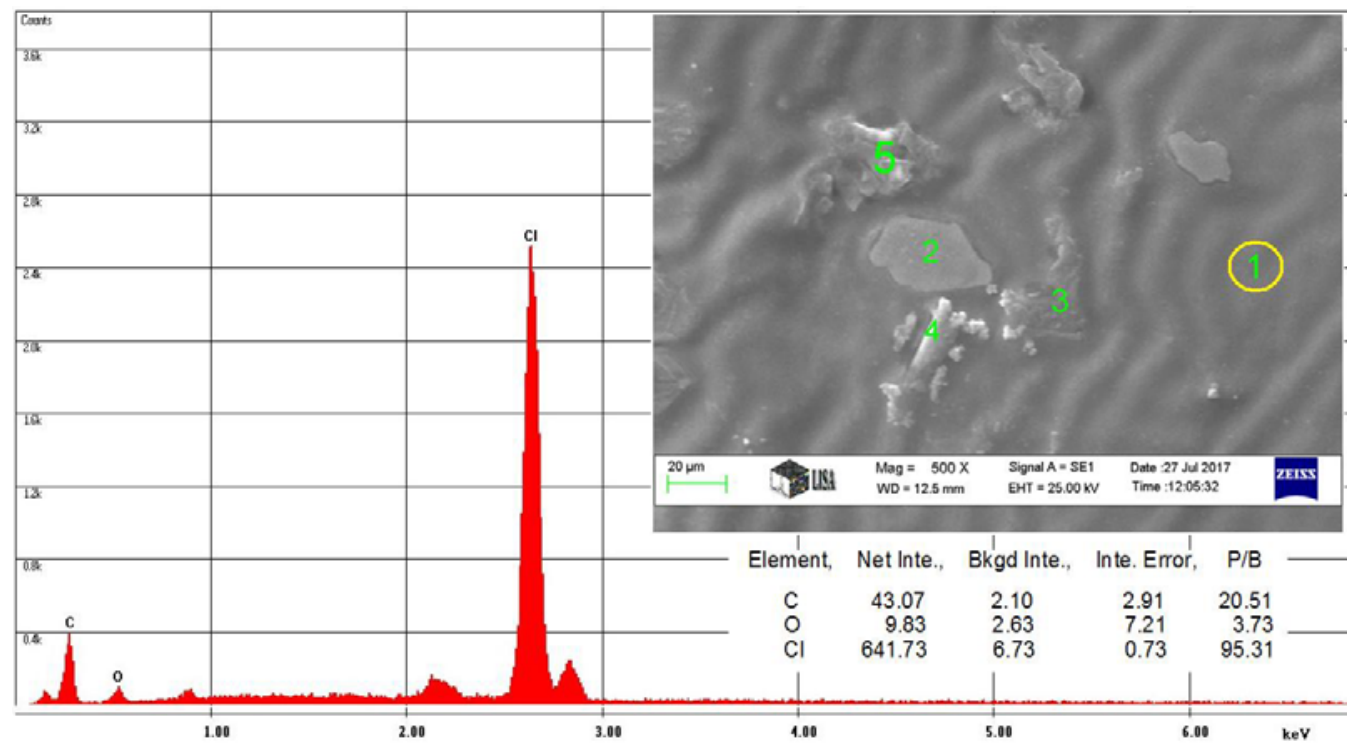

Fig.4 Energy-dispersive X-ray spectroscopic micro-analyser (EDS) of point.1 in SEM image for the sample mixed by hand 


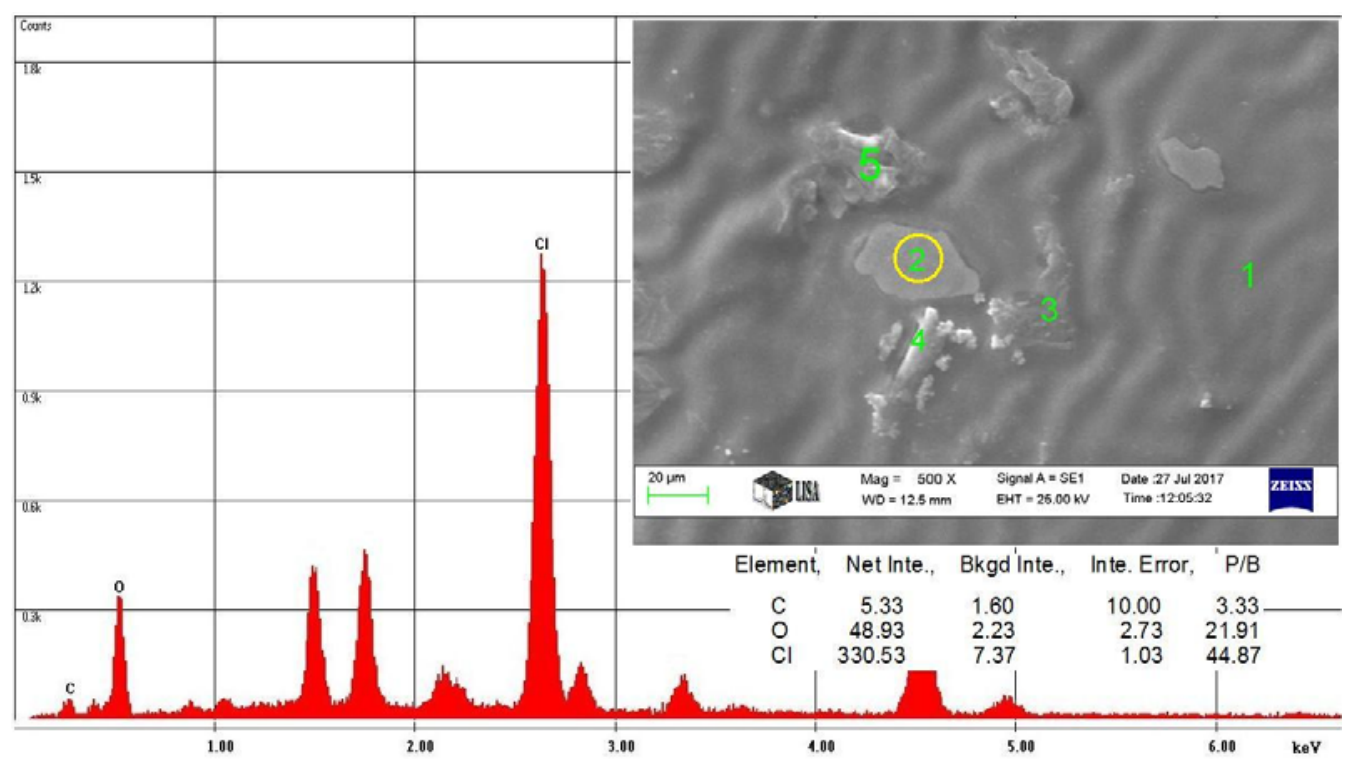

Fig.5 Energy-dispersive X-ray spectroscopic micro-analyser (EDS) of point.2 in SEM image for the sample mixed by hand

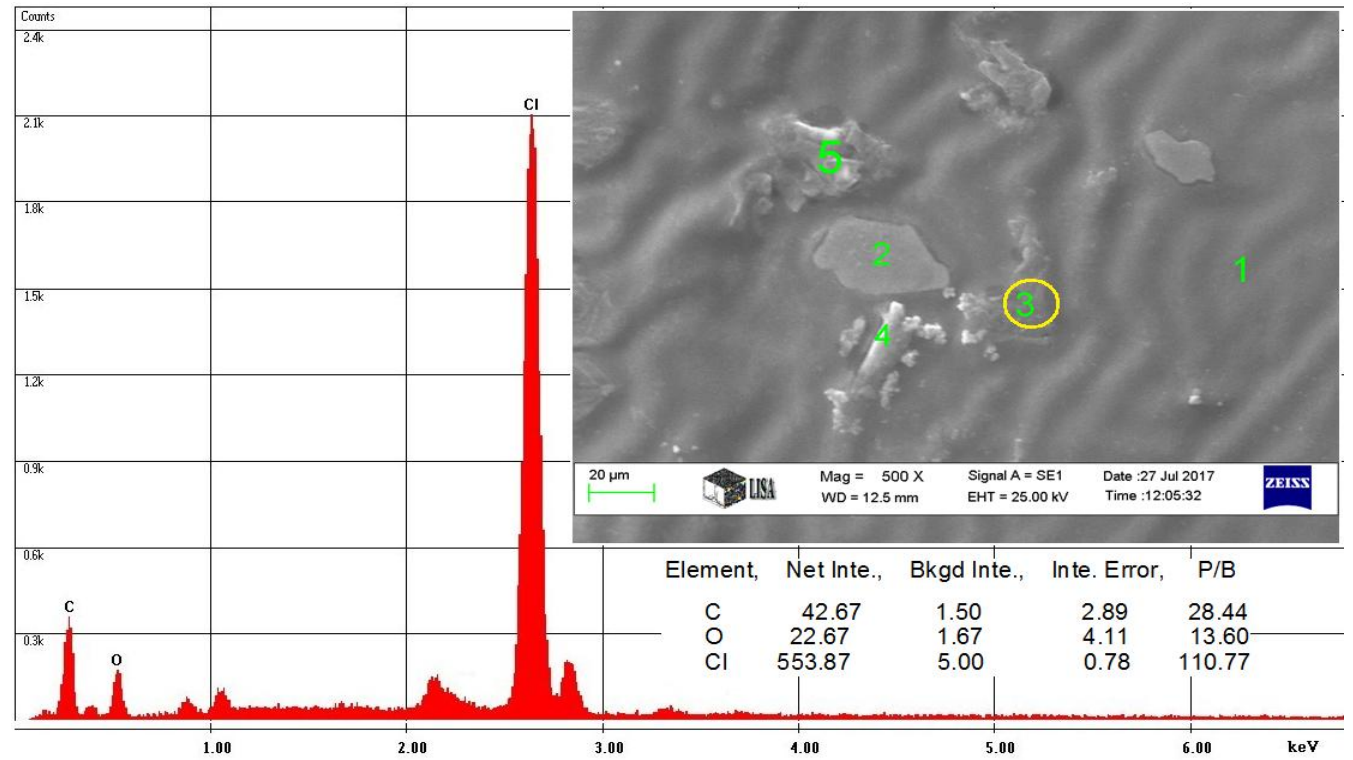

Fig.6 Energy-dispersive X-ray spectroscopic micro-analyser (EDS) of point.3 in SEM image for the sample mixed by hand 


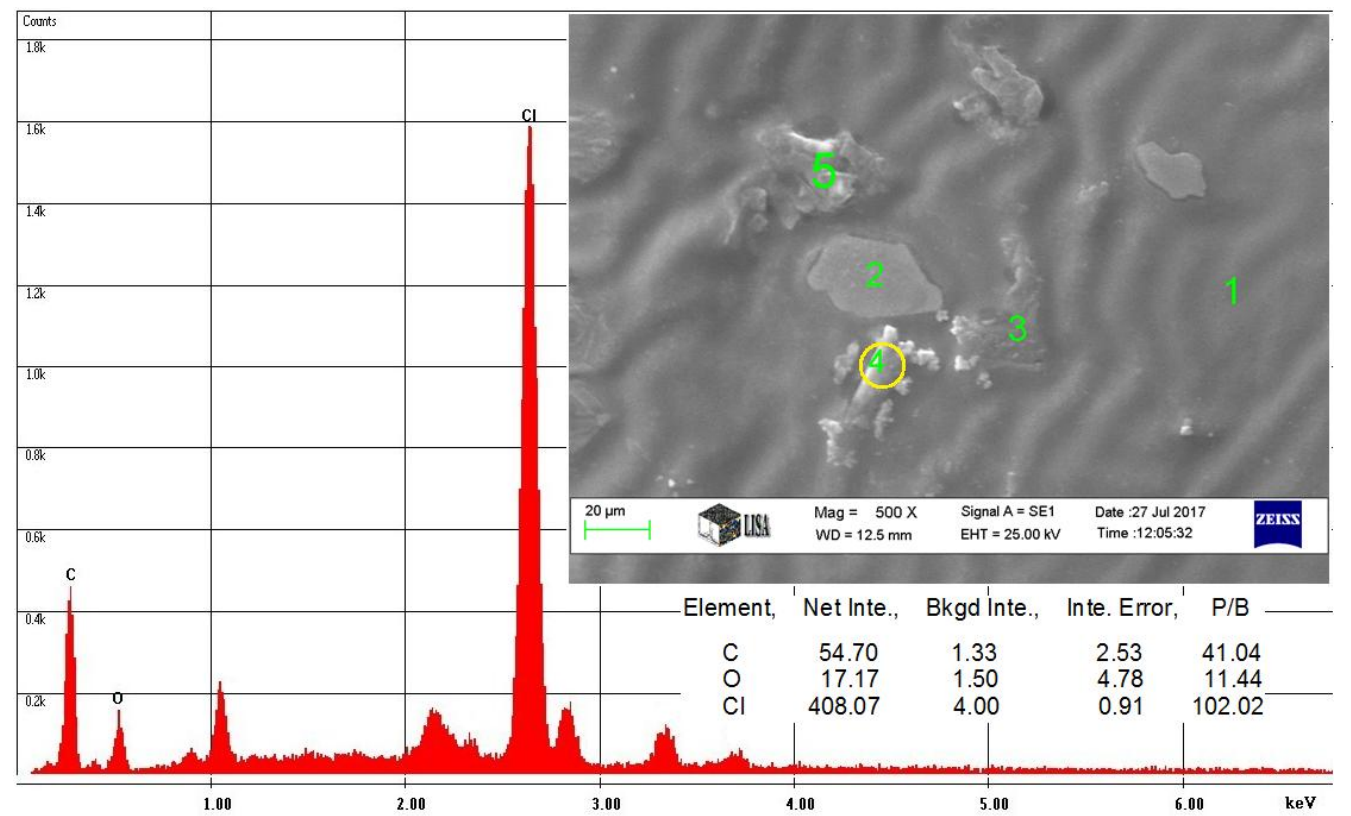

Fig.7 Energy-dispersive X-ray spectroscopic micro-analyser (EDS) of point.4 in SEM image for the sample mixed by hand

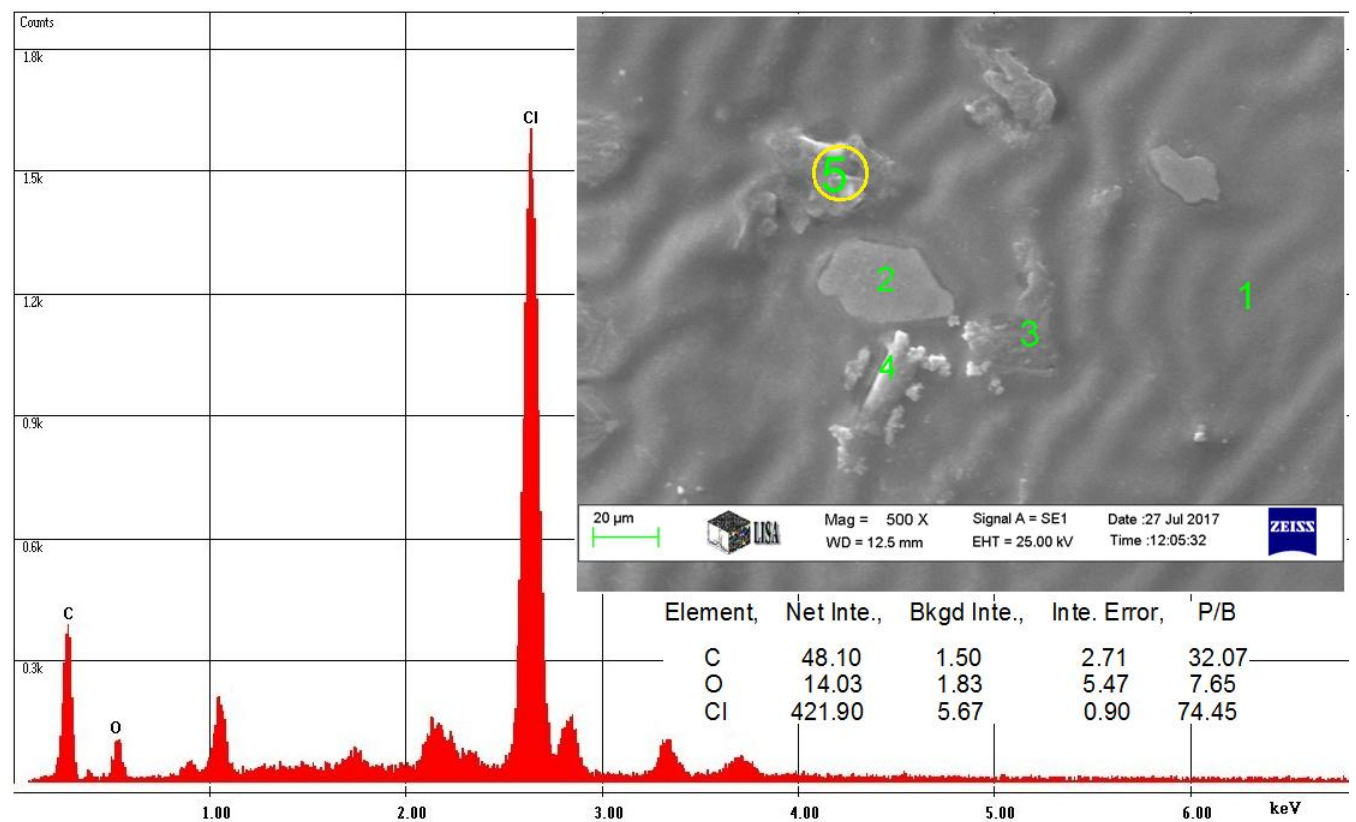

Fig.8 Energy-dispersive X-ray spectroscopic micro-analyser (EDS) of point.5 in SEM image for the sample mixed by hand 


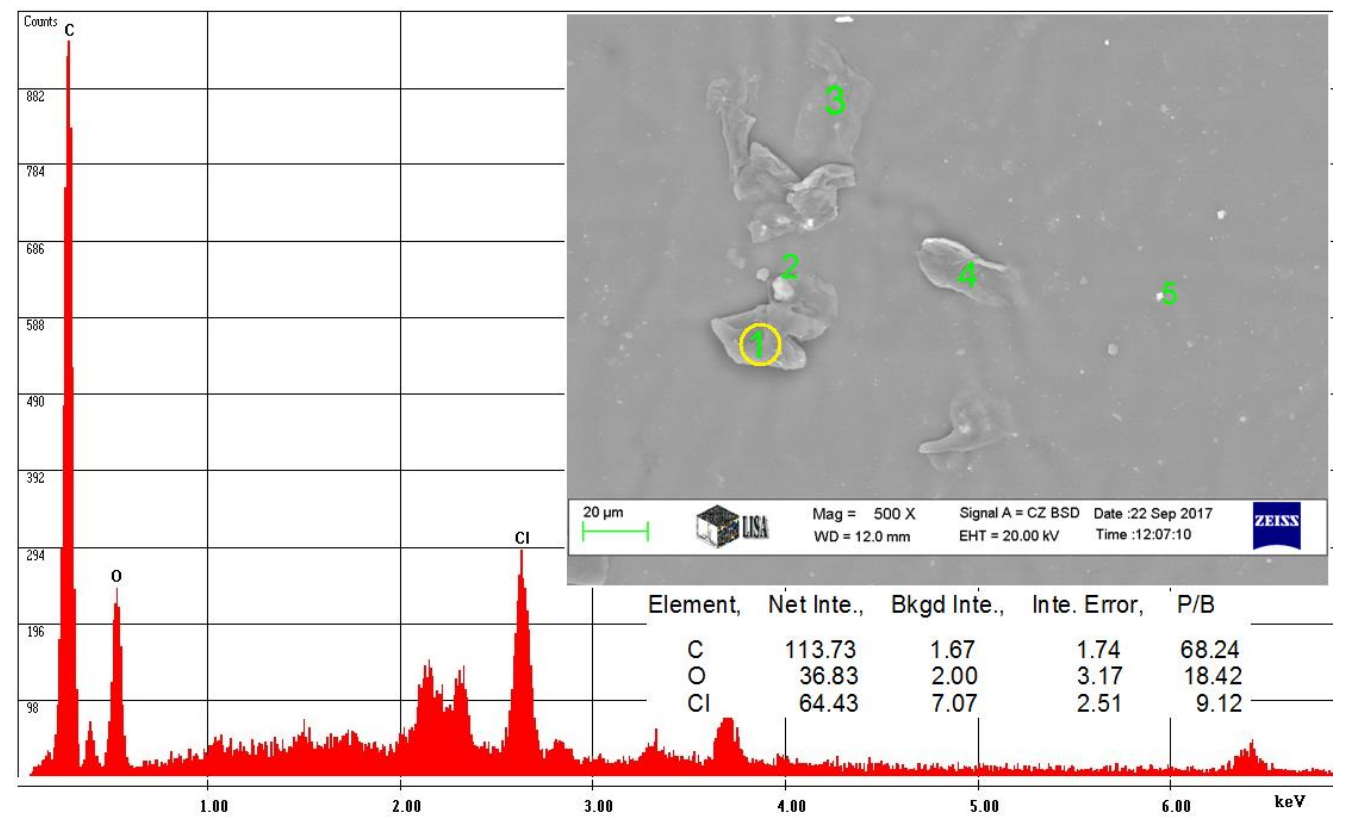

Fig.9 Energy-dispersive X-ray spectroscopic micro-analyser (EDS) of point.1 in SEM image for the sample mixed by mechanical mixer

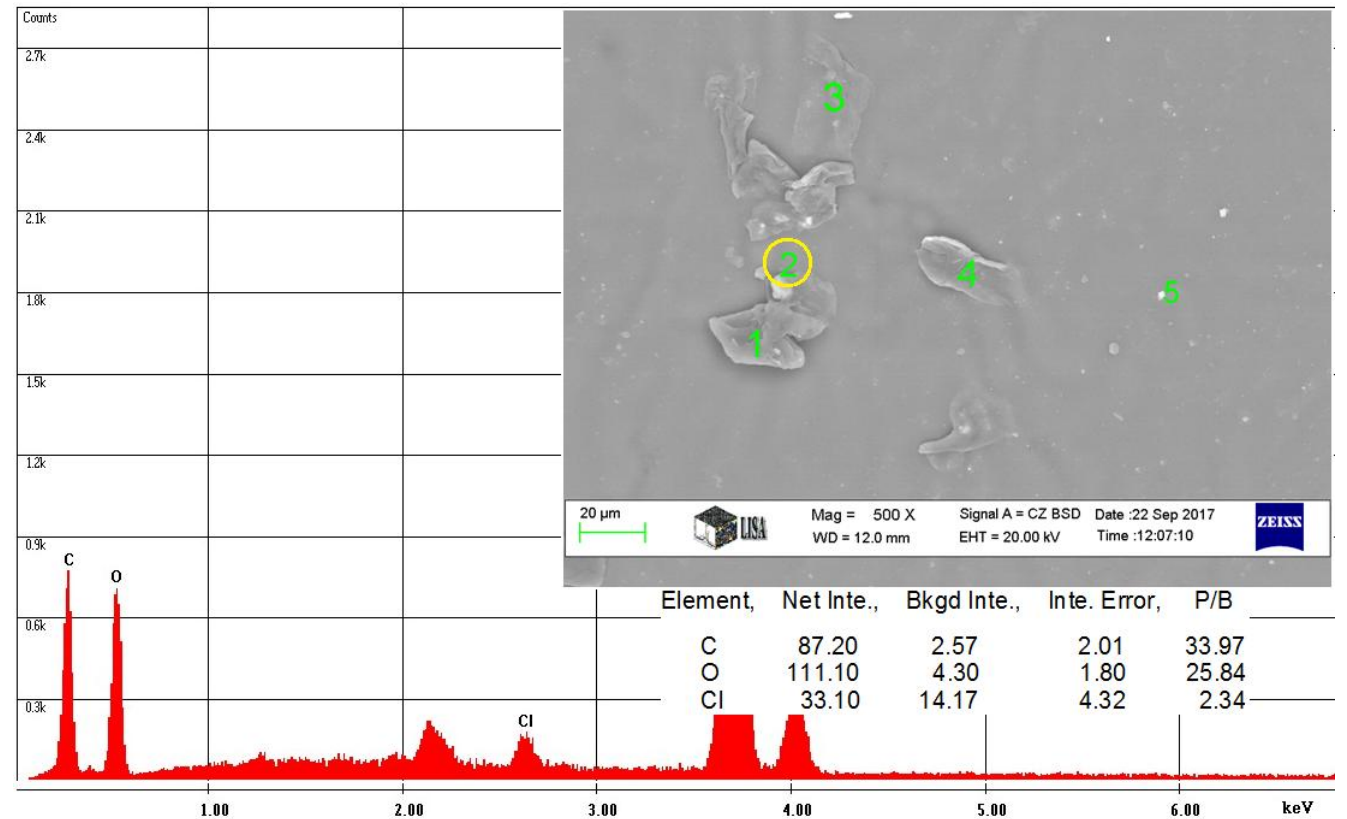

Fig.10 Energy-dispersive X-ray spectroscopic micro-analyser (EDS) of point.2 in SEM image for the sample mixed by mechanical mixer 


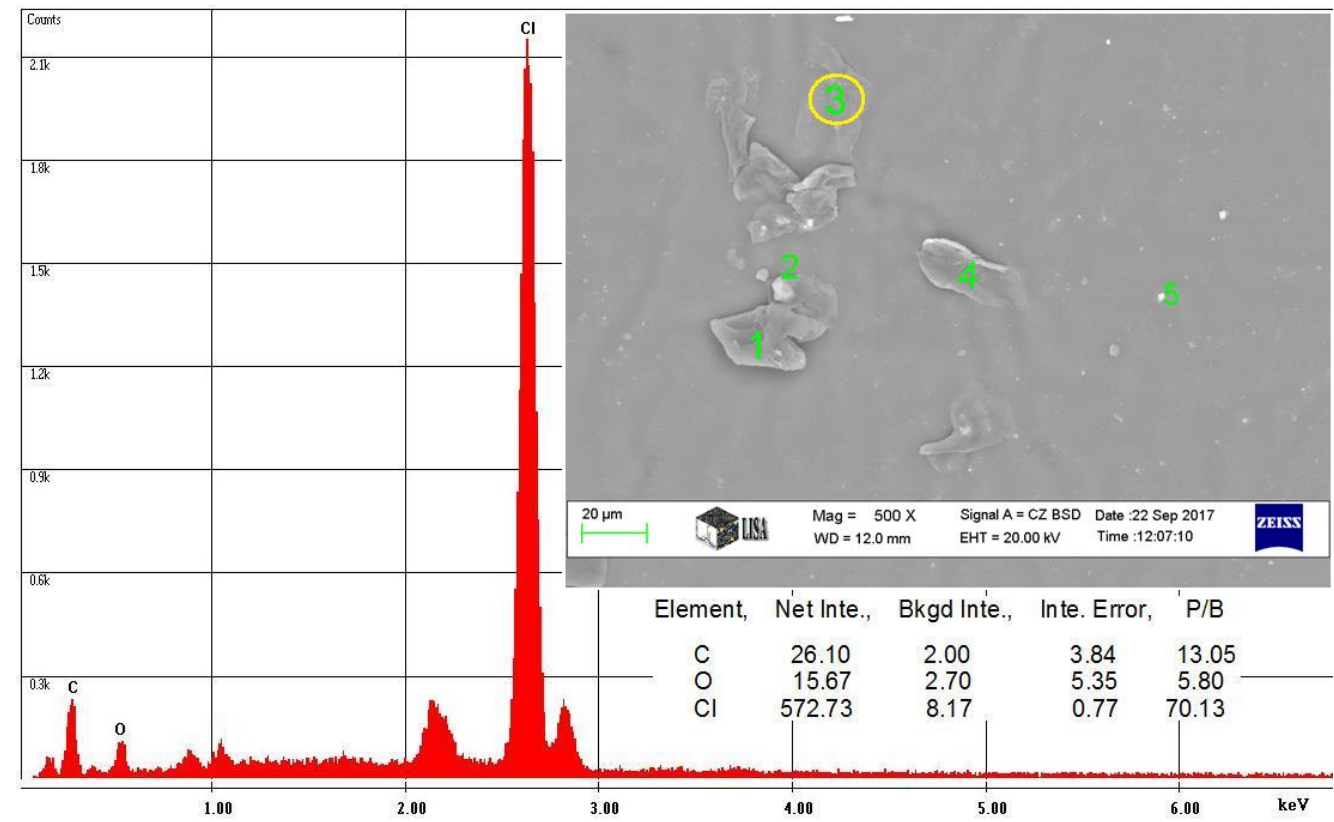

Fig.11 Energy-dispersive X-ray spectroscopic micro-analyser (EDS) of point.3 in SEM image for the sample mixed by mechanical mixer

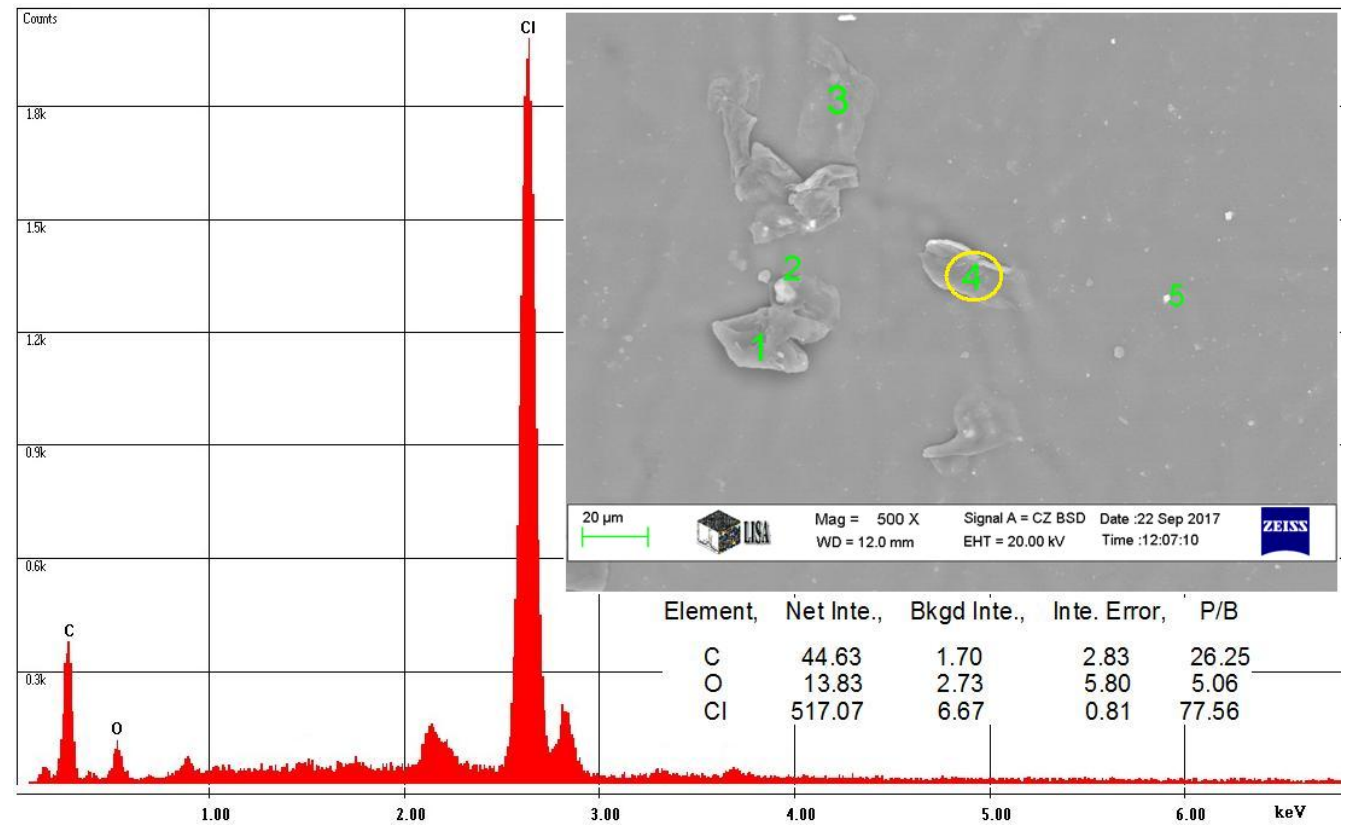

Fig.12 Energy-dispersive X-ray spectroscopic micro-analyser (EDS) of point.4 in SEM image for the sample mixed by mechanical mixer 


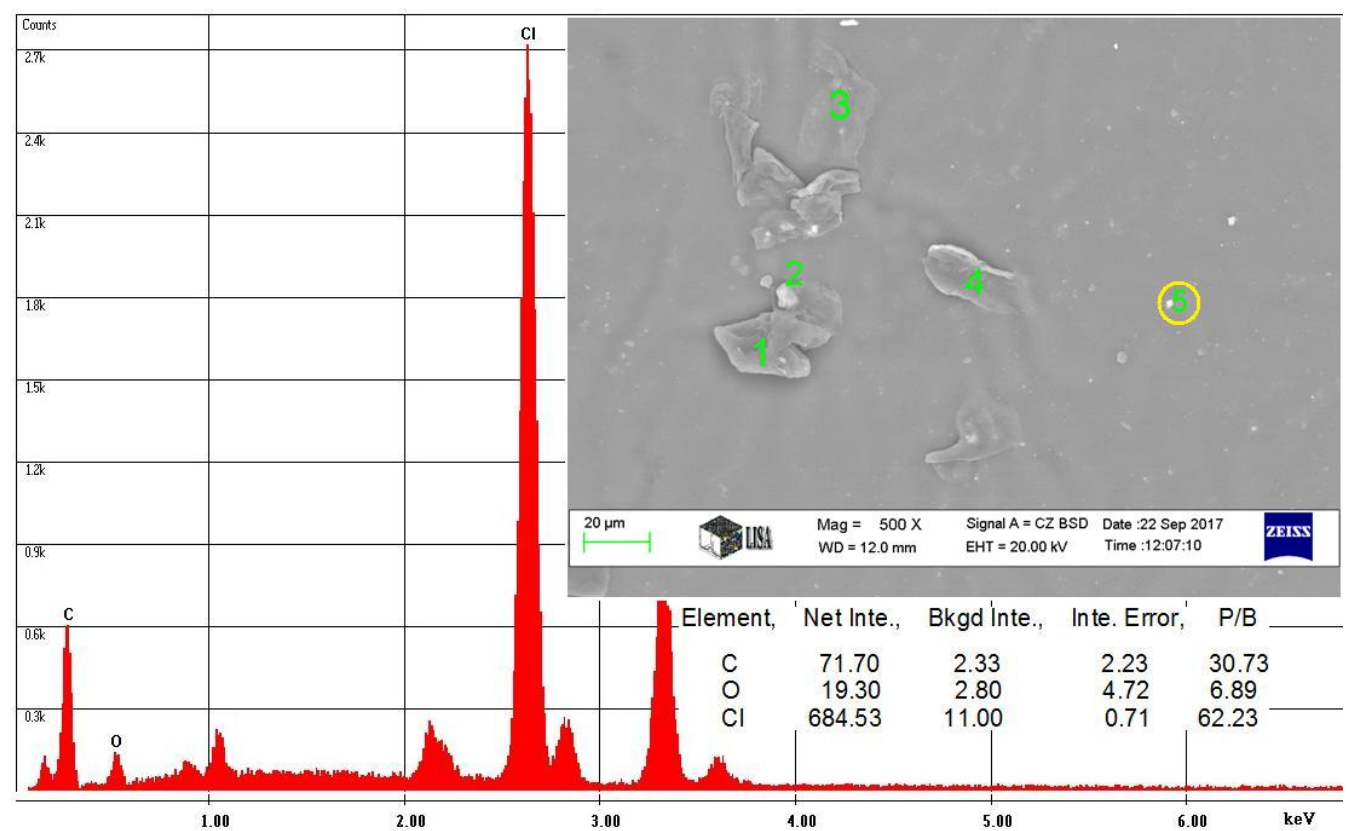

Fig.13 Energy-dispersive X-ray spectroscopic micro-analyser (EDS) of point.5 in SEM image for the sample mixed by mechanical mixer

\section{Conclusions}

From the results obtained from the LOI and thermal stability test we noted that the limiting oxygen index for sample mixed by hand higher than the sample mixed by mechanical mixer and also the hand-mixed sample has color stability better than that mixed by mixer due to the non homogonous distribution of components causing in conglomerated the $\mathrm{Cl}, \mathrm{C}$, and $\mathrm{O}$, as indicated in scanning electron microscopy (SEM) images and the energydispersive X-ray spectroscopic micro-analyzer (EDS) test. Gelation grade of PVC mixing by mechanical mixer is higher than PVC mixing by hand.

\section{ACKNOWLEDGEMENTS}

We would like to thank everyone who helped us to complete this research including technicians working with Csaba Kónya and Gabriella Szemere at the BorsodChem company as well as Árpád Kovach at the laboratory of scanning electron microscopy, University of Miskolc.

\section{REFERENCES}

[1] J. C.Morley and R.F. Grossman, Flame Retardants and Smoke Suppressants, Chapter 16 in Grossman, R.F., (Ed.), Handbook of Vinyl Formulating, $2^{\text {nd }}$ edition, John Wiley and Sons, New York, N.Y., pp. 403-414, 2008. ISBN 978-0-471-71046-2, DOI: 10.1002/9780470253595.ch16

[2] A. W. Coaker, "Fire and Flame Retardants for PVC," Journal of Vinyl \&Additive Technology, vol. 9, no. 3, pp. 403-115, 2003.

[3] D. D. Drysdale, SFPE Handbook of Fire Protection Engineering, in DiNenno P.J., (Ed.), Boston and Quincy, MA: SFPE and NFPA, pp. 1-149, 1988.

[4] A.I. Al-Mosawi, J.K. Ahmed, and H.A. Hussain, Evaluation flame retardancy of epoxy composite by using design of experiments, in OPTIROB 2012, 2012, Applied Mechanics and Materials, vol.186, pp 156-160, 2012. DOI: 10.4028/www.scientific.net/AMM.186.156.

[5] Jr. A.Rodolfo and L.H. Innocentini-Mei, "Smoke suppression of PVC and copper (II), molybdenum and zinc oxides mixtures: TG/MS and TG/FTIR studies," in Proc.PVC 2017, 2017, p. 25-27.

[6] A.I. Al-Mosawi, "Study using of antimony trioxide material as a flame retardant material," M.Sc thesis, Babylon university, Iraq, 2003.

[7] Fire and polyvinyl chloride - Vinyl in Design, The Vinyl Institute, A Division of The Society of the Plastics Industry, Inc.65 Madison Avenue, Morristown, New Jersey, 1996.

[8] A.I. Al-Mosawi, Flammability of composites ,Chapter 14, in Njuguna, J. (ed.) Lightweight composite structures in transport: Design, manufacturing, analysis and performance. UK: Woodhead Publishing, pp.361-369. ISBN: 978-1-78242-325-6 (print), ISBN: 978-178242-343-0 (online).

[9] S. Ayaz, M. Ishaq, K. Saeed, I. Ahmed, and N. K. Khalil, "Investigation of Thermal, Mechanical and Electrochemical Properties of Nanocomposites Based on CuO Modified Poly(vinyl chloride)/Poly(methyl methacrylate) Blend," Journal of Vinyl \& Additive Technology, vol.23, issue.2, pp.80-85, 2015. DOI: 10.1002/vnl.21488.

[10] A.I. Al-Mosawi, Flame Retardancy of Polymers: Experimental Papers ,LAP LAMBERT Academic Publishing ,2012 , ISBN: 25531 $659-3-978$.

[11] A.I. Al-Mosawi, "Formation hybrid flame retardant and its effect on thermal resistance of araldite resin composite," Academic research international, vol. 3, no.2, pp.66-69, 2012.

[12] A.I.Al-Mosawi, A.I.Al-Zubadi, M.H. Al-Maamori, and N. M.Al-Maimuri, "Fire Retardants for Civil Structures," Global Journal of Researches in Engineering: C,Chemical Engineering, vol.13, issue.2, pp. 8-12, 2013.

[13] N. Nakajima and S-Y. Kwak, "Effect of Plasticizer Type on Gelation and Fusion of PVC Plastisol, Dialkyl Phthalate Series," Journal of Vinyl Technology, vol.13, no.4, 1991, pp. 212-222. DOI: 10.1002/vnl.730130411. 